\title{
Xenotransplantation of porcine neonatal islets of Langerhans and Sertoli cells: a 4-year study
}

\author{
Rafael A Valdés-González ${ }^{1,4}$, Luis M Dorantes ${ }^{3}$, G Nayely Garibay ${ }^{3}$, Eduardo Bracho-Blanchet ${ }^{2}$, \\ Armando J Mendez ${ }^{5}$, Roberto Dávila-Pérez ${ }^{2}$, Robert B Elliott ${ }^{6}$, Luis Terán ${ }^{4}$ and David J G White ${ }^{7}$ \\ ${ }^{1}$ Facultad de Medicina, Universidad Nacional Autónoma de México, and ${ }^{2}$ Department of Surgery, ${ }^{3}$ Department of Endocrinology, ${ }^{4}$ Xenotransplant \\ Laboratory of the Hospital Infantil de México 'Federico Gómez', México, D.F. Mexico, ${ }^{5}$ Diabetes Research Institute, University of Miami, Miami, FL, USA, \\ ${ }^{6}$ Diatranz Ltd, Auckland, New Zealand and ${ }^{7}$ Robarts Research Institute, University of Western Ontario, Ontario, Canada
}

(Correspondence should be addressed to Rafael A Valdés-González, Laboratorio de xenotrasplantes, $4^{\circ}$ Piso Edif. Mundet, Hospital Infantil de México 'Federico Gómez', Calle Dr. Márquez 162, Col Doctores, C.P. 06720 México, D.F. Mexico; Email: rvaldes@xenomexico.org)

\begin{abstract}
Objective: Porcine islets of Langerhans for xenotransplantation into humans have been proposed as a solution to the shortage of human donors. Rejection is one of the main constraints. This study presents the results of a clinical trial using a novel method for transplanting and immunoprotecting porcine islets in type 1 diabetic patients.

Design: A 4-year follow up of a clinical trial involving 12 patients, with no immunosuppressive drugs at any point. Eleven age matched untransplanted diabetics served as controls.

Methods: We have developed a procedure for protecting neonatal porcine islets by combining them with Sertoli cells and placing them in a novel subcutaneous autologous collagen-covered device. Results: In the patients in the treatment group, no complications arose and no porcine endogenous retrovirus infection was detected. Half of the patients showed a significant reduction in insulin requirements compared with both their pre transplant levels and controls, and this reduction was maintained for up to 4 years. Two patients became insulin-independent for several months. Porcine insulin was detected in three patients' sera following glucose stimulation up to 4 years post transplant. Three years post transplant, one of four devices was removed from four patients, and the presence of insulin-positive cells in the transplant was demonstrated by immunohistology in all 4 patients. Conclusions: Long-term cell survival with concurrent positive effects on metabolic control are possible by this technique.
\end{abstract}

European Journal of Endocrinology 153 419-427

\section{Introduction}

Tight metabolic control in the type 1 diabetic patient is very difficult to achieve, despite the undisputed progress in treatment modalities. Sub-optimal control of carbohydrate metabolism leads to the earlier onset and faster development of diabetic complications. In order to re-establish glycemic control in type 1 diabetic patients, whole organ pancreas transplantation has routinely resulted in normoglycemia (1), although this technique is associated with significant co-morbidity (2). More recently, allotransplantation of isolated islets of Langerhans in combination with systemic immunosuppression has been demonstrated to be an effective method for restoring carbohydrate control and there are several active programs developing this technique (3). However, given the great shortage of organs of cadaver origin, the possibility of xenotransplantation of porcine islets has been proposed as a solution. To date, there has been limited successful experience with islet xenotransplantation, most notably the work of Groth and co-workers (4) where they transplanted fetal porcine islets either intraportal or under the renal capsule of diabetic patients receiving a human kidney transplant with immunosuppression. These studies failed to demonstrate any effects on insulin requirements, although porcine C-peptide was detected in the urine of four of ten patients for over 300 days. In one patient, who had had the islets placed under the capsule of the transplanted kidney, a biopsy obtained 3 weeks after the islet transplantation revealed viable insulin staining cells. In xenotransplantation there are two major obstacles. The first is the presence of a porcine endogenous retrovirus (PERV) incorporated in all porcine genomes (5) that could theoretically infect the recipient. The second is the immunological barrier, since the pig has specific antigens such as $\alpha$-Gal and others to which all humans 
are sensitized. (6). Recent discoveries have caused us to re-evaluate these assumptions. By now several studies have shown that PERV is most probably innocuous. Thus, no transmission of PERV has been found in primates and human patients that received porcine derived products shown to contain PERV (7-10). Furthermore, the $\alpha$-Gal antigen is not ubiquitously present in all porcine cell types, and in particular it is not expressed on the beta cells of the islets of Langerhans nor in the Sertoli cells in the testicle (11). The immunomodulating activity of Sertoli cells for use in islet transplantation was first described by Selawry et al. in 1985 (12). Subsequently, Suárez-Pinzón et al. (13) were not only able to identify an immunomodulating factor (transforming growth factor (TGF)- $\beta$ 1) secreted by these cells, but reported that Sertoli cells have an ability to protect transplanted islets by both local acting and distal mechanisms. We have developed a collagen-generating device in which transplanted cells are provided with a suitable environment for the cells to survive, with good vascularisation while avoiding direct contact with the blood. This device has been successfully tested, first in islet autotransplants in pigs and later in a rat model (14). A current point of controversy is the optimal location for transplanting islets of Langerhans. Clinical allotransplants are injected into the portal vein, a procedure which may have serious consequences such as bleeding and thrombosis and portal hypertension including statosis (15). Experimentally, many different sites have been proposed as suitable locations for Islet transplantation. These vary from the metabolically logical, such as the liver (16) and spleen (17), to the convenient, such as the kidney capsule (18) and omental pouch (19), to immunologically privileged, such as the testis (20). Locating the islets subcutaneously has also been advocated $(21,22)$. In the present study, we report the results of xenotransplants to type 1 diabetic patients of neonatal porcine islets of Langerhans protected with porcine Sertoli cells inside an autologous collagen-generating device placed subcutaneously in the anterior abdominal wall.

\section{Subjects and methods}

\section{Clinical trial: regulation and informed consent}

The clinical trial was regulated by the ethics and research committees of the Hospital Infantil de México and the Facultad de Medicina of the Universidad Nacional Autónoma de México, as well as the National Transplant Center and the National Bioethics Committee of the Health Ministry. These committees also reviewed and approved the trial, and determined that it and the consent forms were in agreement with national and international guidelines, including the Helsinki Declaration. All potential trial participants had the risks associated with the trial explained to them in three group sessions and a series of personal interviews. They were then given a previously authorized informed consent letter, to be signed by both the patients and their parents. The patients underwent psychological evaluation to determine the likelihood of compliance with the monitoring regimen (23).

\section{Patients}

Twelve adolescent type 1 diabetic patients were accepted. Their mean age was 14.7 years (range $11-$ 17) and they had been diabetic for a mean of 6.7 years (range 4-10 years). Basal human C-peptide for all patients' values was below $0.15 \mathrm{ng} / \mathrm{ml}$, except in one patient where $0.23 \mathrm{ng} / \mathrm{ml}$ was recorded pre transplant. Glycosylated hemoglobin had a mean of $10.9 \%$ (range 6.6-14.3).

\section{Experimental Design}

All patients were scheduled to receive a first transplant and if they achieved near or total insulin-independence they would continue to be followed up and no further treatment would be given. In those patients in whom a minimal or no response was seen, a second transplant was performed 6 months after the first transplant. A third transplant was performed in four patients 3 years following their original graft. In these patients one of the original devices was removed allowing histological examination of the original transplant.

Immediately upon entering the study, the patients followed a diet and exercise regimen standard for diabetic patients, with periodic weight and height measurements. The patients were instructed to record blood glucose determinations seven times a day (pre- and postprandial, and at 3 a.m.). An ageand disease-matched control group $(n=11)$, was subjected for 10 months to exactly the same exhaustive endocrinological monitoring, and diet and exercise program, but without receiving a transplant. This was done to control for any changes in exogenous insulin requirements resulting from this tight control and monitoring.

\section{Cell Preparations}

Donor animals Male 7-10 day old piglets were used. The animals were bred in New Zealand in a specific pathogen-free environment in accordance with the Association for Assessment and Accreditation of Laboratory Animal Care. Sera from the donor piglets and their sows were analyzed for pathogens, as described elsewhere (24). Islets and Sertoli cells were isolated there and flown at room temperature in culture media to Mexico, where they were cultured for 1 day prior to transplantation. 
The techniques for isolating porcine islets of Langerhans and Sertoli cells have been described elsewhere (25-29). Briefly, islets were prepared following Elliott et al. (8) and Valdés et al. (29) using liberase digestion. The islet cells (measured in Islet Equivalents (IEQ)) were placed in RPMI-1640, 2\% HSA, 0.12\% nicotinamide, and ciproxine $(1.5 \mathrm{mg} / \mathrm{l})$, at room temperature and centrifuged at 1000 r.p.m. for $20 \mathrm{~min}$. The average islet yield was 157860 IEQs/g of pancreas (s.D.: 36593 ), and 290730 IEQs/pancreas (S.D.: 75 570). The purity of the islets was in all cases $>85 \%$ as calculated with dithizone staining, and viability was $>85 \%$, as determined by acridine orange/propidium iodide staining. Sertoli cell-enriched testicular cells were prepared by a method described by Valdés et al. (26), placed in DMEM media with $0.12 \%$ nicotinamide and ciproxine (1.5 mg/l) added. All cell preparations underwent full microbiologic screening both in New Zealand and again at the time of transplantation. Cells from ten neonatal pigs were used for each transplant. Sertoli cells and islets were mixed together immediately prior to transplantation.

\section{Xenotransplantation}

Two collagen-generating devices were implanted subcutaneously in the upper anterior wall of the patient's abdomen under general anesthesia. The devices consist of $6 \times 0.8 \mathrm{~cm}$ surgical grade stainless steel mesh tubes, with a polytetrafluoroethylene (PTFE) rod in its interior (14). The rod ends in a stopper, and there is another stopper at the other end. The devices were left in place for two months to allow formation of vascularized collagen tissue that completely surrounded and penetrated the devices. Two months after the placement of the devices, the transplant procedure was carried out under general anesthesia by exposing the end of each device, removing the PTFE rod and infusing into the space left by withdrawal of the rod 250000 islets of Langerhans with 30-100 Sertoli cells per islet. The number of islets per kilogram ranged from 13927 to 20833 IEQ/kg body weight, with a mean of 17798 and S.D. of 1819.99. The device was then sealed with a small PTFE cap. This approach proved to be simple and relatively non-invasive, in that it allowed the cells to be transplanted with only a small subcutaneous incision.

From 6 to 9 months later, all patients, except one who chose not to re-transplant, received a second Sertoli cell and islet transplant into two previously implanted new devices. Recently, four patients had one of the originally implanted devices removed after 3 years, in order to receive a third transplant. The decision for these third transplants was prompted by the fact that these patients showed a noticeable decrease in insulin requirement, and we hypothesized that a third transplant might further reduce their insulin requirements, perhaps providing them with independence from insulin therapy. The histology obtained from these devices is reported here. No immunosuppressive drugs were administered at any point.

\section{Patient monitoring}

The patients and their household family members were monitored quarterly for the presence of PERV DNA and RNA in their peripheral blood using PCR and RT-PCR (30). In addition, they were all screened for the presence of anti-PERV antibodies by enzyme-linked immunosorbent assay (ELISA) (31). The sensitivity and specificity of these assays were similar in the samples taken from the donor pigs to those reported elsewhere (31). Other serology tests included cytomegalovirus, hepatitis A, B, and C, rubella, Epstein-Barr virus, and Toxoplasma gondii and were carried out quarterly.

Patients were monitored daily for blood glucose levels, exogenous insulin requirements and glycosylated hemoglobin levels. Human insulin and porcine C peptide (Linco Research, St Charles, MO, USA) in serum levels were determined after an intravenous glucose tolerance test (IVGTT) with $0.5 \mathrm{~g} / \mathrm{kg}$ glucose pre transplant and at 1,3 and 5 months post transplant. Porcine insulin (by high performance liquid chromatography (HPLC), see below) was measured in one patient at 28 months and in two patients 4 years after the initial transplant.

\section{Immunological studies}

Humoral immune responses to the transplanted tissue were monitored by measurement of anti-Gal antibodies by ELISA (13). Measurements were taken pre transplant and at $1,2,4,6$, and 8 weeks after the transplant, and monthly thereafter. Flow cytometry for quantification of lymphocyte subtypes was carried out using a four color Becton Dickinson Facscalibur system (Rockville, MD, USA). Serum complement levels were determined pre transplant, and at 3 months and 3 years post transplant. The $\mathrm{C} 3 \mathrm{~b}$ fraction was detected by nephelometry in a Boering BN-II system (Deerfield, IL, USA).

\section{Histological examination}

The tissue from the four excised devices was analyzed by immunohistochemistry for insulin, glucagons, and lymphocyte sub-populations using formalin-fixed, paraffinembedded $5 \mu \mathrm{m}$ sections. Sections were screened with monoclonal primary antibodies and developed with peroxidase-diaminobencidine (DAB) reaction with hematoxilin counterstaining. After fixing the cells, $1 \mathrm{hr}$ incubation at room temperature was performed with goat anti-mullerian inhibiting substance (MIS, a specific marker for Sertoli cells) primary antibodies, and mouse secondary antibodies. 


\section{Porcine insulin detection}

A standard was prepared by spiking $200 \mu \mathrm{l}$ serum with $10 \mu \mathrm{l}$ human and porcine insulin followed by 1:10 dilution. As additional controls, a normal human serum sample and the same serum with the addition of $0.12 \mathrm{pmol} / \mathrm{l}$ porcine insulin were processed in parallel with unknowns. Separation was monitored by trace $\mathrm{I}^{125}$ insulin added to the sample. The diluted serum ( $2 \mathrm{ml}$ ) was applied to a $600 \mathrm{mg}$ C4 Wide Pore solidphase extraction column (Delta Technical Des Plaines, IL, USA), and eluates were lyophilized, reconstituted, and centrifuged to remove insoluble materials. Each sample $(120 \mu \mathrm{l})$ was injected onto a Supelco Wide Pore C8 column $(150 \times 4.6 \mathrm{~mm}$, particle size $3 \mu \mathrm{m})$ with a $20 \times 4.0 \mathrm{~mm}$ guard column using a Waters HPLC system (Milford, MA, USA). Fractions $(0.5 \mathrm{ml})$ were reconstituted and used directly for insulin assay (HI-11K Linco Research, St Charles, MO, USA). The antibody detects human insulin and has 90\% crossreactivity with porcine insulin. The detection limit is 0.12 pmol insulin per assay tube.

\section{Anti porcine C-peptide antibodies}

Negative controls were pooled human serum from nontransplanted patients and serum from non-transplanted diabetic patients. Sera samples were tested for anti porcine $\mathrm{C}$ peptide antibodies by radioimmunoassay (Linco Research Inc.).

\section{Statistical analysis}

In order to establish that the procedures did not impact on normal growth of the patients, their body mass index was monitored, and converted to a percentile corrected for sex and age using the data corresponding to the Center for Disease Control (USA) standards. Statistical analysis was carried out using students' $t$-test for one-sample comparisons against a baseline. For analysis of multiple measurements over time, a repeated-measures ANOVA with Scheffe post hoc multiple comparisons was carried out. On the basis of insulin requirements, a hierarchical cluster analysis with squared euclidian distance method was used. Glycemic control was analyzed as percentage of monthly fasting morning measures that fell in the normal (70$140 \mathrm{mg} / \mathrm{dL})$, elevated $(140-250 \mathrm{mg} / \mathrm{dL})$, or adverse range (high $>250$ and hypoglycemia, $<70 \mathrm{mg} / \mathrm{dl}$ ) and was tested with the $\chi^{2}$ independence test. A $P<0.05$ was considered to be significant.

\section{Results}

Follow up of metabolic control strict control of diet and exercise in the control patients resulted in a small overall increase in their insulin requirements and a decrease in total $\mathrm{HbA} 1$, indicating a lack of control prior to their recruitment. In the transplanted patients, following the first transplant and, more markedly, after the second, cluster analysis revealed that two distinct insulin requirement patterns appeared (Fig. 1), identifying two subgroups of patients. Half of the patients (group A) had a $50 \%$ or greater reduction in their insulin requirements (mean \pm S.E.M.: 1 year post transplant, $-72.46 \% \pm 9.7 ; 2$ years post transplant, $-68.50 \% \pm 8.6$ ), and the other six patients (group B) showed a slight increase (1 year, 15.71\% \pm 9.15 ; 2 years; $22.56 \% \pm 11.68)$. This increase seen in the group B patients corresponded with that seen in the control group (at 10 months, $16.67 \% \pm 14.42$ ). Since groups A and B self-selected on the basis of their insulin requirements, statistical differences between them would not have meaning, since the patients were not randomly assigned to their respective groups. However, this sorting does not affect how each individual behaves with respect to their original insulin requirements, so differences between each group and their pre transplant requirements represents an effect of the procedure. The insulin requirements in both groups (Fig. 1) measured after the second transplant (6-9 months) showed significant differences (one sample $t$-test) to their base line values, with group A having decreased requirements $(P<0.01)$ and group $\mathrm{B}$ increased requirements $(P<0.05)$. Additionally there was significant difference $(P<0.001)$ between group $A$ and the control group (repeated measures ANOVA) from the first month post transplant onwards. Group $\mathrm{B}$ and the control group showed no significant differences. Two patients in group A became transiently insulin independent. The first one was a 15 year old female patient who had exogenous insulin requirements of $61 \mathrm{IU} /$ day before the transplant, with mean fasting blood glucose levels of $104.0 \pm 7.3 \mathrm{mg} / \mathrm{dL}$ ( \pm S.D.) and HbA1c levels at $13.4 \%$. After the first transplant, she reduced her requirements by $73 \%$, adjusted according to her blood glucose levels. After the second transplant she began to have intermittent periods of 3-5 days, alternating between periods of no insulin injections, followed by periods of $1-2 \mathrm{IU} /$ day.

This pattern lasted for 3 months. During this period, mean blood glucose levels were at $110.1 \pm 6.97 \mathrm{mg} / \mathrm{dL}$ and $\mathrm{HbAlc}$ was at $9.6 \%$. After these 3 months she began to need to have subtle but constant increments in her requirements and she currently has a $40 \%$ reduction, with $\mathrm{HbA1c}$ levels at $8.6 \%$. The second patient was a 16 year old female with pre transplant values at $55 \mathrm{IU} /$ day, fasting blood glucose of $110.7 \pm 23.4 \mathrm{mg} / \mathrm{dL}$, and $\mathrm{HbA} 1 \mathrm{c}$ of $12 \%$. Six months after the first transplant, the patient showed a 6 week reduction to $1-3 \mathrm{IU} / \mathrm{day}$ and then began to increase her requirements to a $70 \%$ reduction. During this period, the blood glucose levels were at $127.2 \pm 16.0 \mathrm{mg} / \mathrm{dL}$ and $\mathrm{HbA} 1 \mathrm{c}$ was $6.8 \%$. Eight weeks after the second transplant she showed a reduction to $2-3 \mathrm{IU} /$ day, and 2 months later she was totally free of insulin for two consecutive months. During this period her glucose levels were $104.8 \pm 5.6 \mathrm{mg} / \mathrm{dL}$, and her 


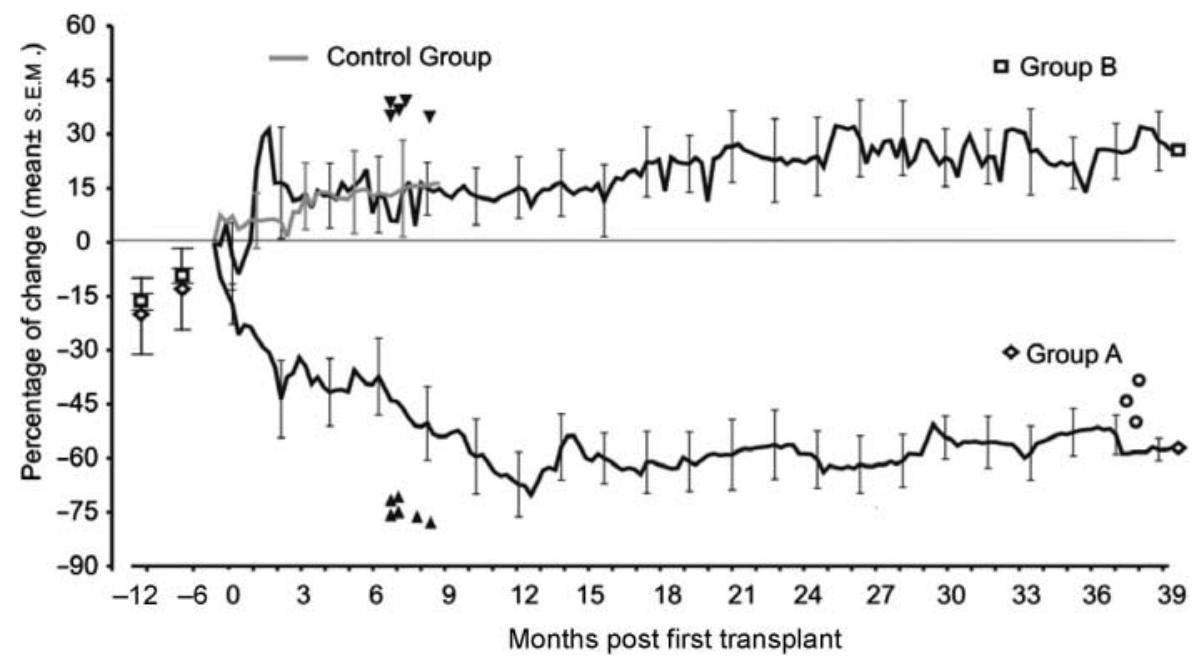

Figure 1 Insulin requirements for each group, shown as a percentage of the pre transplant levels ( \pm S.E.M.). Group A, six patients with insulin reduction post transplant; group B, six patients who showed insulin decrease post transplant; group C, 11 age- and diseasematched controls. The first two points are the values for the average 1 year and 6 months pre transplant and there are no statistical differences between the groups. There are statistically significant differences at 1 month post transplant in each of the groups and their pre transplant baseline (group B and Control, increased insulin requirement; group A, reduced insulin requirement). Group A is significantly lower than control from month 9 onwards. Arrowheads indicate second transplants and open circles indicate third transplants in group A.

HbA1c was $6.5-7.8 \%$. After these 62 days, she began to require 1-2 IU/day, and her requirements rose until at 4 years after the first transplant she still showed a $51.82 \%$ reduction. These patients received 13927 and 17857 $\mathrm{IEQ} / \mathrm{kg}$ body weight, respectively. Blood glucose levels in groups A and B remained mostly between normal and elevated for the duration of the pre and post transplant period (Fig. 2). There were no statistical differences between the groups at any point in time. The lack of clear differences between the groups is due to the fact that all patients had their insulin requirements adjusted in order to bring them towards the normal range. What is relevant was that group A maintained normal levels despite the reductions in the exogenous insulin administration. In both groups A and B, glycosylated hemoglobin reduced significantly $(P<0.05)$ from the time they entered the protocol, prior to transplantation (Table 1). Post transplant, both groups maintained their improved glycosylated hemoglobin levels regardless of the decrease in the insulin requirements to group A.

\section{Evidence of graft function}

Measurement of serum porcine C-peptide never revealed levels which would have been consistent with a functioning islet transplant (some values are positive pre transplant) nor with the observed reductions in exogenous insulin shown in group A (Table 1). To investigate the possibility that this was due to rapid clearance as a result of an immune response, an assay for antibody to porcine C-peptide was developed. The results (Table 1) show that low levels of anti-porcine C-peptide antibodies could be detected in some patients, both pre and post transplant.
It seems unlikely, however, that these antibodies could account for the absence of detectable porcine C-peptide in these patients. This possible lack of reliability of porcine C-peptide as an indicator of graft function prompted us to measure porcine insulin directly using an HPLC technique (human and porcine insulin differs by one amino acid or 30 Daltons).

Immunoreactive insulin with coincident migration after HPLC to authentic porcine insulin was detected in three patients tested so far. The samples were taken 28 months $(n=1)$ and four years $(n=2)$ after original transplant. The samples showed two peaks, and in the 28 month case it represent a baseline (Fig. 3A) and 50minute post IVGGT (Fig. 3B). The levels of porcine insulin increased from 1.2 to $3 \mathrm{pmol}$ in response to the glucose stimulation. Human insulin was also detected, since the patient had received $25 \mathrm{IU}$ of $\mathrm{NPH}$ insulin in the preceding $24 \mathrm{~h}$, however the levels of human insulin did not rise with glucose stimulation, in contrast to the response seen with porcine insulin. Although the technique does not allow for accurate estimation of total serum porcine insulin concentration, it is noteworthy that porcine insulin rose to higher levels than those of the therapeutic dose of human insulin. The other two patients sera were analyzed only for the peak sample and the results were very similar.

\section{Histology}

Four patients from group A, including the three patients with detectable porcine insulin, had a device removed at the time of a third transplant, as indicated in Fig. 1. Immunohistochemistry of the tissue extracted from the 


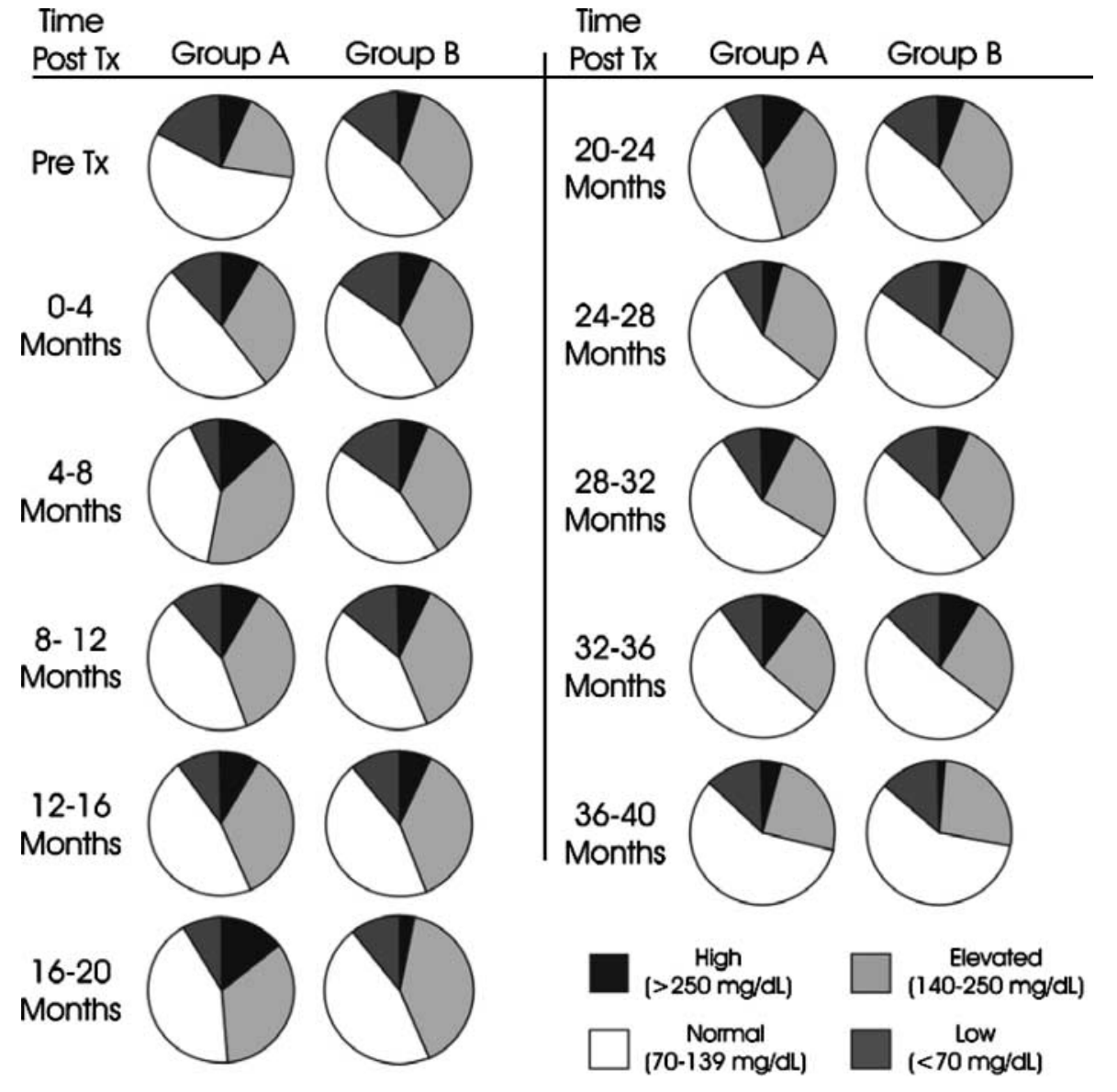

Figure 2 Percentage of capillary blood glucose level measurements on the fasting morning sample that fell in the high $(>250 \mathrm{mg} / \mathrm{dL})$, elevated (140-250), normal (70-139), or low $(<70)$ range over the course of the pre and post transplant follow up of both transplanted groups. There were no statistical differences. interior of the device stained positive for insulin-producing cells in all four patients. Glucagon positive cells were also detected in three of the removed devices, and one is pending processing. The overall architecture of the islets was to a large extent destroyed, with insulinpositive cells seen (Fig. 4A) distributed throughout the collagen matrix, which showed substantial vascularity. No insulin-positive cells were seen in the tissue removed from outside the device. Also, glucagon positive cells could be detected (Fig. 4E). In Figs $4 \mathrm{~A}$ and B, insulin positive cells are shown associated with an infiltrate of CD3 T cells, however, insulin positive cells were also found in

Table 1 Columns show total glycosylated hemoglobin ( $\mathrm{HbA} 1)$ as mean percentage ( \pm S.E.M.), levels of basal human $\mathrm{C}$ peptide (HcP $(\mathrm{ng} / \mathrm{ml}))$, and number of patients with detectable porcine $\mathrm{C}$ peptide (PcP) and anti porcine C peptide antibodies (PcP Ab). The number of patients with high $(\mathrm{H})$ levels (twofold over diabetic controls) or low $(\mathrm{L})$ levels $(50 \%$ higher than controls) is shown. In all cases the $\mathrm{HcP}$ was $<0.5 \mathrm{ng} / \mathrm{ml}$ (values under $0.8 \mathrm{ng} / \mathrm{ml}$ indicate a diabetes diagnosis) and the PcP was $<0.4 \mathrm{ng} / \mathrm{ml}$, but not interpretable due to positivity in the pre transplant period. There were no significant differences between groups $A$ and $B$.

\begin{tabular}{|c|c|c|c|c|c|}
\hline & Group & Mean HbA1 (\% $\%$ S.E.M.) & $\operatorname{HcP}(n)(\mathrm{ng} / \mathrm{ml})$ & $\mathbf{P c P}(n)$ & PcP Ab \\
\hline \multirow[t]{2}{*}{ Pre Tx } & A & $11.02( \pm 0.71)$ & $(4)<0.15(1)=0.23$ & 2 & $2 \mathrm{H}, 2 \mathrm{~L}$ \\
\hline & B & $10.80( \pm 1.13)$ & $(5)<0.15$ & 3 & $1 \mathrm{H}, 4 \mathrm{~L}$ \\
\hline \multirow[t]{2}{*}{ Month 1} & A & $9.40( \pm 0.51)$ & $(4)<0.15(1)=0.23$ & 2 & 4L \\
\hline & B & $9.05( \pm 0.71)$ & $(5)<0.15$ & 3 & $1 \mathrm{H}, 3 \mathrm{~L}$ \\
\hline \multirow[t]{2}{*}{ Month 6} & A & $8.53( \pm 0.43)$ & $(4)<0.15(1)=0.45$ & 3 & $2 \mathrm{H}, 1 \mathrm{~L}$ \\
\hline & B & $8.09( \pm 0.5)$ & $(5)<0.15$ & 2 & $1 \mathrm{~L}$ \\
\hline \multirow[t]{2}{*}{ Month 12} & A & $9.56( \pm 0.96)$ & $(5)<0.15(1)=0.23$ & 2 & $\mathrm{nt}$ \\
\hline & B & $8.80( \pm 0.23)$ & $(5)<0.50$ & nd & nt \\
\hline \multirow[t]{2}{*}{ Month 24} & A & $8.82( \pm 0.78)$ & $(4)<0.15(1)=0.26$ & 2 & $\mathrm{nt}$ \\
\hline & B & $8.61( \pm 0.75)$ & $(5)<0.15$ & nd & nt \\
\hline \multirow[t]{2}{*}{ Month 36} & A & $9.13( \pm 1.14)$ & $(4)<0.15(1)=0.23$ & nd & nt \\
\hline & B & $7.83( \pm 0.29)$ & $(5)<0.15$ & nd & nt \\
\hline
\end{tabular}

nd, not detected; nt, not tested. 


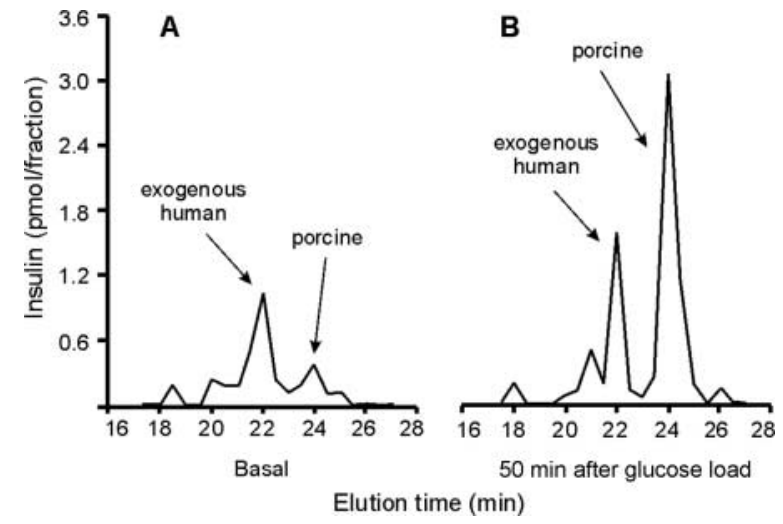

Figure 3 Porcine and human insulin detected in a representative patient's serum during an intravenous glucose tolerance test 28 months post transplant. Panel A shows baseline levels before glucose stimulation, and panel $B$ shows levels 50 min post stimulation. The patient administered $25 \mathrm{IU} /$ day NPH insulin at the time of the intravenous glucose tolerence test (IVGTT). Worth noting is that the area under the human insulin peak is nearly equal for both samples, while the porcine insulin peak increases several-fold.

areas devoid of lymphocyte infiltration (data not shown). We were unable to stain the sections satisfactorily for apoptosis. Tcell infiltrates were predominantly CD8 positive (Fig. 4D) with relatively few CD 4 positive cells seen (Fig. 4C) Staining for CD 25 was positive in one patient. The presence of Sertoli cells (stained for MIS) was seen in three of the analyzed devices (Fig. 4F), pending the processing of a fourth.

\section{Immune responses}

All of the patients showed an elicited response to Gal antibodies in both the IgM and IgG isotypes. Following the first transplant, the mean anti Gal IgM titer from all the patients rose from a baseline titre of 1/90 (S.E.M. \pm 9.1$)$ to $1 / 180( \pm 12)$ at 1 month and following the second transplant from $1 / 85( \pm 10)$ to $1 / 186$ $( \pm 41)$. There was no difference in IgM responses between groups $\mathrm{A}$ and $\mathrm{B}$. Gal IgG responses to the initial transplant were not significantly different between the two groups with the mean titer for all patients rising from $1 / 153( \pm 33)$ to $1 / 3223( \pm 961)$ at 1 month. Following a second transplant, group A patients exhibited a significantly lower $(P=0.03) \operatorname{Ig} G$ titer at 1 month post transplant, 1/1632 ( \pm 688$)$ compared with group B patients, $1 / 4361( \pm 66)$. Complement levels were similar in both groups pre transplant (group A, $147 \pm 16 \mathrm{mg} / \mathrm{dl}$; group B, $160 \pm 19 \mathrm{mg} / \mathrm{dl}$ ), at 3 months post transplant (group A, $144 \pm 11 \mathrm{mg} / \mathrm{dl}$; group B, $155 \pm 3 \mathrm{mg} / \mathrm{dl}$ ), and after 3 years (group A, $114 \pm 8 \mathrm{mg} / \mathrm{dl}$; group B, $116 \pm 7 \mathrm{mg} / \mathrm{dl}$.)

\section{Safety}

Routine microbiological screening of both patients and close family have been consistently negative, although
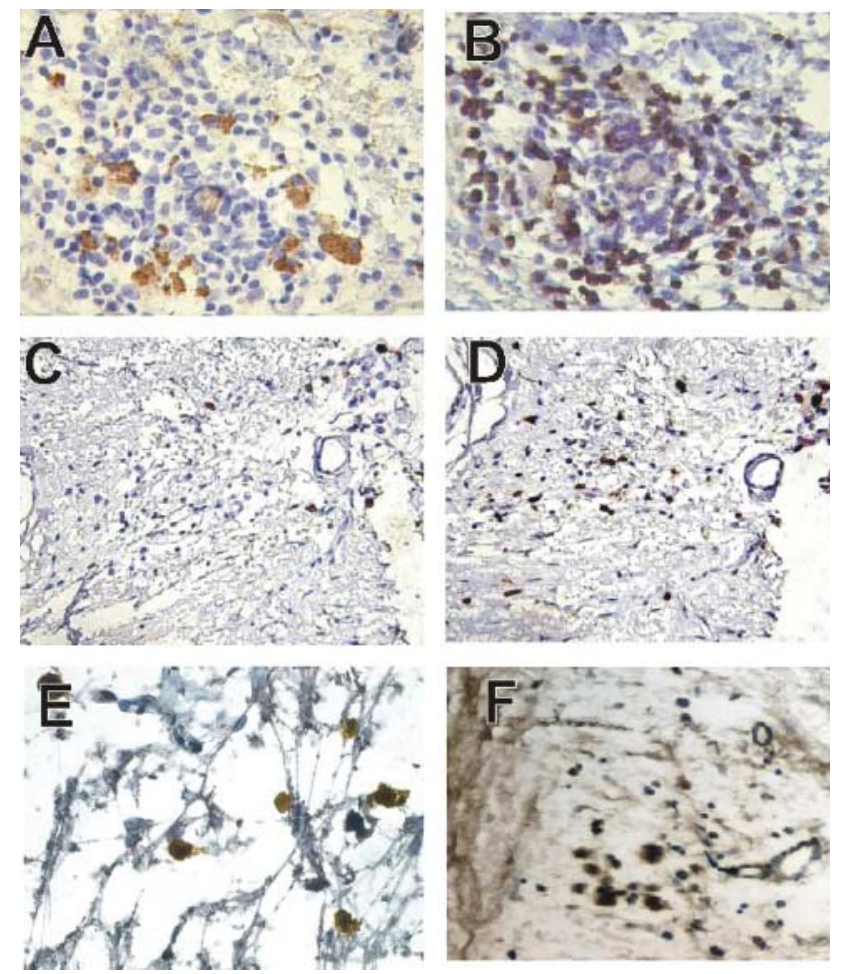

Figure 4 Histological sections from tissue from inside the devices removed from patients after three years. Panel A shows insulinpositive cells and panel $B$ shows infiltration of CD3 lymphocytes in the subsequent section to panel $A$. Panels $C$ and $D$ show sequential sections stained for CD4 and CD 8, respectively. Panel E shows glucagons-positive cells and panel F shows MIS-positive Sertoli cells.

two patients did exhibit transient chimerism as evidenced by porcine DNA thru PCR. No complication related to the surgery or to the presence of the cells has occurred at any time.

Finally, the mean body mass index percentile was $64.8 \%$ (S.D. \pm 5.55 ) at the beginning of the study and $63.8 \%( \pm 4.89)$ after 4 years, which indicates that body mass in all the patients has not changed from the original pre transplant percentile; there were no significant differences between groups A and B, nor the control.

\section{Discussion}

Our data show that a subgroup (50\%) of recipients of porcine islets significantly reduced their requirements for exogenous insulin, with two patients achieving transient insulin-independence. No such reduction was seen in any of the 11 age-matched controls who were subjected to the same monitoring regimen but did not receive a transplant. Our data also suggests that this reduction in insulin-independence was not a placebo effect of the transplant itself. Glycosylated hemoglobin and blood glucose levels in the group A patients have remained stable throughout the study (despite reductions in their exogenous insulin), glucose-stimulated immunoreactive porcine insulin was detectable 
in the serum of three patients, and biopsies from four group A patients stained positive for insulin-producing cells. Perhaps the most noteworthy aspect of these experiments is the presence of insulin and glucagon secreting cells 3-4 years after the implant, as well as the simultaneous prevalence of lymphocytes, mainly $\mathrm{CD} 3+$ and $\mathrm{CD} 8+$, which are considered cytotoxic. There was no neutrophil infiltration as seen in other islet xenotransplantation models (30). We are currently engaging in a quantitative analysis of the histological findings in order to determine if there is a correlation between $\beta$ cell mass and exogenous insulin reductions. It is clear that there must be an important immunomodulation, presumably produced by the Sertoli cells or impact of the collagen protective matrix, particularly in light of the results of the serology against the Gal antigen. In this way, through an ELISA, we can see that there is a rise in IgG and IgM titers immediately after the first transplant. However, in a surprisingly short period of time (less than 6 months) the titers are reduced to their baseline values.

We compared our patients' sera with those reported by Groth and co-workers (4) and carrying out the exact same hemagglutination technique that they used to show elevated titers after 6 to 8 years after transplanting porcine islets in humans, we found that our patients had very low values, in particular, our highest responder was almost identical to their lowest. Unfortunately, we have not been able to correlate these antibody levels with function. We have not detected any clinical signs of immunodepression, like those seen in patients using drugs in order to avoid rejection, nor any variations in lymphocyte subpopulations, immunoglobulins or complement, or increased susceptibility to infections or their development.

It is noteworthy that previous attempts at islet xenotransplantation in humans failed due, presumably, to rejection, despite the use of an intense immunosuppressive regimen (4). The fact that all our patients remained within the growth lane percentile at which they started the protocol further suggests that the procedure had no deleterious effect on their overall health, and that the reduction in insulin requirements observed in group A can not be attributable to changes in eating or exercise habits.

The question of why we detected two distinct patient groups after the transplant remains unanswered. We have examined as candidate variables the blood group, presence of anti-insulin antibodies, age, gender, and time from diagnosis, without finding any conclusive results.

Failure to detect porcine C-peptide consistently in any of the transplant patients remains to be clarified. This could be due to an anomalous sensitivity of the commercial test when used in conjunction with human serum, or immune clearance of the C-peptide. The fact that we were able to detect porcine C-peptide pre transplant illustrates these limitations. We were able to demonstrate the presence of porcine C-peptide antibodies in some of the patients; however, this alone could not account for the consistent absence, since antibodies were not detected in the majority of the patients or consistently in any patient.

The reduction in the level of glycosylated hemoglobin that occurred in all the patients during the pre transplant period indicates that being recruited into the protocol alone had a beneficial effect. That glycosylated $\mathrm{Hb}$ levels did not become elevated in the group A patients stands as a testament that the reductions seen in exogenous insulin were not at the expense of elevated blood sugars. The increase in insulin requirements needed to maintain blood sugar and glycosylated $\mathrm{Hb}$ targets seen in the group $\mathrm{B}$ patients and controls is typical for diabetic adolescents. Although the insulin requirements together with the histological and lab assays seen in group A, clearly show that long term function of pig islets transplanted to the diabetic patients is feasible, we are posed with the challenge of increasing the number of responding patients and of making these reductions reflect an even better improvement in the overall metabolic control, since the values of glycosylated hemoglobin did not improve or worsen significantly with respect to group B. We suspect that overconfidence in members of group A in the face of their declining requirements may have made them less compliant with the dietary and exercise program. However, they all diminished notably from their base line values.

We are aware that there are still many important issues to be solved before xenotransplantation can become a reliable therapy for type 1 diabetes, but we feel that the approach described here has delivered valuable information. This is a procedure that has proven to be safe and without complications, either endocrinological, immunological or microbiological. It is important to highlight the fact that, 4 years after the patients were xenotransplanted, and without the use of immunosuppressive drugs, we have been able to detect insulin-secreting cells in the device, persistent reductions in insulin requirements in several patients, and the presence of glucose-stimulated secretion of porcine insulin in the serum of the three patients we have tested.

\section{Acknowledgements}

This work was supported in part by CONACyT donation J002/761/00. The authors would like to thank B Garcia and S Sun for assistance with the histology, L S Copeman for measurement of anti-Gal antibodies, D Cooper and G Weir for critical review of this manuscript. We thank Diatranz Ltd New Zealand for donating the cells. 


\section{References}

1 Gruessner AC \& Sutherland DE. Analysis of United States (US) and non-US pancreas transplants reported to the United Network for Organ Sharing (UNOS) and the International Pancreas Transplant Registry (IPTR) as of October 2001. Clinical Transplantation $2001141-72$.

2 Sutherland DE, Gruessner RW, Dunn DL, Matas AJ, Humar A, Kandaswamy R, Mauer SM, Kennedy WR, Goetz FC, Robertson RP, Gruessner AC \& Najarian JS. Lessons learned from more than 1,000 pancreas transplants at a single institution. Annals of Surgery 2001233 463-501.

3 Shapiro AM, Lakey JR, Ryan EA, Korbutt GS, Toth E, Warnock GL, Kneteman NM \& Rajotte RV. Islet transplantation in seven patients with type 1 diabetes mellitus using a glucocorticoidfree immunosuppressive regimen. New England Journal of Medicine $2000343230-238$.

4 Groth CG, Korsgren O, Tibell A, Tollemar J, Moller E, Bolinder J, Ostman J, Reinholt FP, Hellerstrom C \& Andersson A. Transplantation of porcine fetal pancreas to diabetic patients. Lancet 1994 344 1402-1404.

5 Blusch JH, Patience C \& Martin U. Pig endogenous retroviruses and xenotransplantation. Xenotransplantation $20029242-251$.

6 Galili U, Shohet SB, Kobrin E, Stults CL \& Macher BA. Man, apes, and Old World monkeys differ from other mammals in the expression of alpha-galactosyl epitopes on nucleated cells. Journal of Biological Chemistry 1988263 17755-17762.

7 Dinsmore JH, Manhart C, Raineri R, Jacoby DB \& Moore A. No evidence for infection of human cells with porcine endogenous retrovirus after exposure to porcine fetal neuronal cells. Transplantation $2000701382-1389$.

8 Elliott RB, Escobar L, Garkavenko O, Croxson MC, Schroeder BA, McGregor M, Ferguson G, Beckman N \& Ferguson S. No evidence of infection with porcine endogenous retrovirus in recipients of encapsulated porcine islet xenografts. Cell Transplantation 2000 9 895-901.

9 Heneine W, Switzer WM, Soucie JM, Evatt BL, Shanmugam V, Rosales GV, Matthews A, Sandstrom P \& Folks TM. Evidence of porcine endogenous retroviruses in porcine factor VIII and evaluation of transmission to recipients with hemophilia. Journal of Infectious Diseases $2001 \mathbf{1 8 3} 648$-652.

10 Denner J. Porcine endogenous retroviruses (PERVs) and xenotransplantation: screening for transmission in several clinical trials and in experimental models using non-human primates. Annals of Transplantation $2003 \mathbf{8} 39-48$.

11 Dor FJ, Cheng J, Alt A \& Cooper DK. Gal alpha 1,3Gal expression on porcine pancreatic islets, testis, spleen, and thymus. Xenotransplantation 20041 101-106.

12 Selawry H, Fajaco $\mathrm{R}$ \& Whittington K. Intratesticular islet allografts in the spontaneously diabetic $\mathrm{BB} / \mathrm{W}$ rat. Diabetes 198534 1019-1024.

13 Suarez-Pinzon W, Korbutt GS, Power R, Hooton J, Rajotte RV \& Rabinovitch A. Testicular sertoli cells protect islet beta-cells from autoimmune destruction in NOD mice by a transforming growth factor-beta1-dependent mechanism. Diabetes $2000 \mathbf{4 9}$ 1810-1818.

14 Valdes R, Martin S, Cravioto A \& Tenopala J. Biological encapsulation as a new model for preservation of islets of Langerhans. Transplantation Proceedings $1998 \mathbf{3 0} 481$.

15 Robertson PR. Islet transplantation as a treatment for diabetes a work in progress. New England Journal of Medicine 2004350 $694-705$.

16 Bhargava R, Senior PA, Ackerman TE, Ryan EA, Paty BW, Lakey JR \& Shapiro AM. Prevalence of hepatic steatosis after islet transplantation and its relation to graft function. Diabetes 200453 1311-1317.

17 Jaeger C, Wohrle M, Federlin K \& Bretzel RG. Pancreatic islet xenografts at two different transplantation sites (renal subcapsular versus intraportal): comparison of graft survival and morphology. Experimental and Clinical Endocrinology Diabetes $1995103123-128$.

18 Scharp DW, Marchetti P, Swanson C, Newton M, McCullough CS \& Olack B. The effect of transplantation site and islet mass on long-term survival and metabolic and hormonal function of canine purified islet autografts. Cell Transplantation $1992 \mathbf{1}$ $245-254$.

19 Kin T, Korbutt GS \& Rajotte RV. Survival and metabolic function of syngeneic rat islet grafts transplanted in the omental pouch. American Journal of Transplantation 20033 281-285.

20 Ferguson J \& Scothorne RJ. Extended survival of pancreatic islet allografts in the testis of guinea-pigs. Journal of Anatomy $19771241-8$.

21 Kawakami Y, Iwata $\mathrm{H}, \mathrm{Gu} \mathrm{Y}$, Miyamoto M, Murakami Y, Yamasaki T, Cui W, Ikada Y, Imamura M \& Inoue K. Modified subcutaneous tissue with neovascularization is useful as the site for pancreatic islet transplantation. Cell Transplantation 20009 $729-732$.

22 Wang W, Gu Y, Hori H, Sakurai T, Hiura A, Sumi S, Tabata Y \& Inoue K. Subcutaneous transplantation of macroencapsulated porcine pancreatic endocrine cells normalizes hyperglycemia in diabetic mice. Transplantation 200376 290-296.

23 Terán-Escandón D, Terán-Ortiz L, Ormsby-Jenkins C, EviaViscarra ML, White DJG \& Valdés- González-Salas R. Psychosocial aspects of xenotransplantation: survey in adolescent recipients of porcine islet cells. Transplantation Proceedings 200537 521-524.

24 Kumar G, Tuch B \& Rawlinson W. Limiting potential infectious risks of transplanting insulin-producing pig cells into humans. Pathology 200234 178-184.

25 Korbutt GS, Elliott JF, Ao Z, Flashner M, Warnock GL \& Rajotte R. Microencapsulation of neonatal porcine islets: long-term reversal of diabetes in nude mice and in vitro protection from human complement mediated cytolysis. Transplantation Proceedings 1997 4 21-28.

26 Valdés-González RA, Silva-Torres ML, Ramirez-González B, Ormsby CE, Terán L \& Ayala-Sumuano JT. Method for evaluating quality of cultured neonatal pig Sertoli cells. Xenotransplantation 200512 316-323.

27 Brandhorst H, Brandhorst D, Hering BJ \& Bretzel RG. Significant progress in porcine islet mass isolation utilizing liberase $\mathrm{HI}$ for enzymatic low-temperature pancreas digestion. Transplantation $199968355-361$.

28 Krickhahn M, Meyer T, Buhler C, Thiede A \& Ulrichs K. Highly efficient isolation of porcine islets of Langerhans for xenotransplantation: numbers, purity, yield and in vitro function. Annals of Transplantation $2001648-54$.

29 Valdés-González RA, Silva-Torres ML, Ramirez-González B, Terán L, Ormsbly CE \& Ayala-Sumuano JT. Improved method for isolation of porcine neonatal pancreatic cell clusters. Xenotransplantation 200512 240-244.

30 Takeuchi Y, Patience C, Magre S, Weiss RA, Banerjee PT, Le Tissier P \& Stoye JP. Host range and interference studies of three classes of pig endogenous retroviruses. Journal of Virology 1998 72 9986-9991.

31 Stephan O, Schwendemann J, Specke V, Tacke SJ, Boller K \& Denner J. Porcine endogenous retroviruses (PERVs): generation of specific antibodies, development of an immunoperoxidase assay (IPA) and inhibition by AZT. Xenotransplantation 20018 $310-316$.

32 Kirchhof N, Shibata S, Wijkstrom M, Kulick DM, Salerno CT, Clemmings SM, Heremans Y, Galili U, Sutherland DER, Dalmasso AP \& Hering BJ. Reversal of diabetes in non-immunosuppressed rhesus macaques by intraportal porcine islet xenografts precedes acute cellular rejection. Xenotransplantation $200411396-407$.

Received 14 December 2004

Accepted 16 June 2005 